\title{
Article \\ Synthesis of a Lignin/Zinc Oxide Hybrid Nanoparticles System and Its Application by Nano-Priming in Maize
}

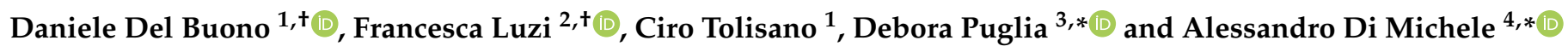 \\ 1 Dipartimento di Scienze Agrarie, Alimentari e Ambientali, University of Perugia, Borgo XX Giugno 74, \\ 06121 Perugia, Italy; daniele.delbuono@unipg.it (D.D.B.); ciro.tolisano@studenti.unipg.it (C.T.) \\ 2 Department of Materials, Environmental Sciences and Urban Planning (SIMAU), Polytechnic University of \\ Marche, Via Brecce Bianche 12, 60131 Ancona, Italy; f.luzi@staff.univpm.it \\ 3 Department of Civil and Environmental Engineering, University of Perugia, Strada di Pentima 4, \\ 05100 Terni, Italy \\ 4 Department of Physics and Geology, University of Perugia, Via Elce di Sotto, 06123 Perugia, Italy \\ * Correspondence: debora.puglia@unipg.it (D.P.); alessandro.dimichele@unipg.it (A.D.M.) \\ + These authors contributed equally to this work.
}

check for

updates

Citation: Del Buono, D.; Luzi, F.;

Tolisano, C.; Puglia, D.; Di Michele, A. Synthesis of a Lignin/Zinc Oxide Hybrid Nanoparticles System and Its Application by Nano-Priming in Maize. Nanomaterials 2022, 12, 568. https://doi.org/10.3390/

nano12030568

Academic Editor: Maria

Pilar Vinardell

Received: 31 December 2021

Accepted: 4 February 2022

Published: 7 February 2022

Publisher's Note: MDPI stays neutral with regard to jurisdictional claims in published maps and institutional affiliations.

Copyright: () 2022 by the authors. Licensee MDPI, Basel, Switzerland. This article is an open access article distributed under the terms and conditions of the Creative Commons Attribution (CC BY) license (https:// creativecommons.org/licenses/by/ $4.0 /)$.

\begin{abstract}
Nanotechnologies are attracting attention in various scientific fields for their technological and application potential, including their use as bio-activators and nanocarriers in agriculture. This work aimed to synthesize a hybrid material (ZnO@LNP) consisting of lignin nanoparticles containing zinc oxide ( $4 \mathrm{wt} \%$ ). The synthesized $\mathrm{ZnO}$ hybrid material showed catalytic effect toward thermal degradation, as evidenced by the TGA investigation, while both spectroscopic and contact angle measurements confirmed a modification of surface hydrophilicity for the lignin nanoparticles due to the presence of hydrophobic zinc oxide. In addition, the antioxidant activity of the ZnO@LNP and the zinc release of this material were evaluated. At the application level, this study proposes for the first time the use of such a hybrid system to prime maize seeds by exploiting the release characteristics of this material. Concerning the dosage applied, ZnO@LNP promoted inductive effects on the early stages of seed development and plant growth and biomass development of young seedlings. In particular, the ZnO@LNP stimulated, in the primed seeds, a higher content of chlorophyll, carotenoids, anthocyanins, total phenols, and a better antioxidant activity, as supported by the lower levels of lipid peroxidation found when compared to the control samples.
\end{abstract}

Keywords: nanotechnology; lignin nanoparticles; zinc oxide; hybrid materials; seed-priming; plant growth; antioxidant activity

\section{Introduction}

The current context requires urgent measures to offer alternative solutions to reduce or avoid the abuse and over-use of natural resources, as their availability is limited [1]. Furthermore, many different anthropogenic activities result in high impact and pressure on natural resources [2]. In this regard, nanotechnologies are gaining a primary role as they offer a wide range of new nanomaterials, paying particular attention to developing new bio-based solutions [3].

Nanomaterials can be obtained applying conventional procedures or, as it is taking place more recently, green synthetic approaches [4]. The former can be generally characterized by a high environmental impact or energy consumption; the latter usually does not impact or use or produce hazardous by-products and have a very affordable cost [3].

Given the nanomaterials' numerous potentialities, the most recent research has, on the one hand, shifted its attention toward biomasses of natural origin, exploring many different ways to valorize these frequently ignored resources [1,5]. Furthermore, the research has started combining different nanomaterials, obtaining hybrid, composite, or coated systems, which offers the possibility of effectively modulating the properties of the 
resulting nanoparticles [6,7]. This last aspect deserves particular attention, as it could offer the possibility to obtain materials that potentiate, modulate, or change particular properties of one or more substances included in the obtained systems [7].

In this context, lignin represents intriguing biomass and a versatile macromolecule, which can be easily scalable to nanostructured forms $[8,9]$. On the planet, lignin is the second most abundant biomass after cellulose and shows a considerable structural variability depending on the botanical origin and characteristics of the species it derives [9,10]. From a structural point of view, lignin shows three central structural phenolic units, and their relative amounts depend on the plant botanical origin [9]. These main structural phenolic motives are indicated as guaiacyl (G), p-hydroxyphenyl (H), and syringyl (S) units [9,11].

Depending on the application, lignin often undergoes chemical reactions that can modify its molecular structure and insert new functional groups, thus opening the perspective of modulating its properties according to the desired results [12]. Nonetheless, only a very small part of the lignin produced as an agricultural or industrial by-product is recycled for some applications [13]. Most of this biomass and the materials derived are disposed of as waste. As a consequence, this can also create environmental issues [13]. Therefore, lignin properties and the possibility to convert and valorize it obtaining interesting technological materials pose more than one question on the opportunity to pay more effort to the recovery and the sustainable valorization of this biomass.

Concerning zinc oxide $(\mathrm{ZnO})$, many applications involve this compound in nanostructured form ( $\mathrm{ZnO}-\mathrm{NP}$ ). For instance, $\mathrm{ZnO}-\mathrm{NP}$ has been used as antifungal, antiviral, and antibacterial, or, for its electronic properties, as an efficient component for developing UV fillers or photochemically active materials [14,15]. ZnO has gained more attention than other oxides to obtain nanomaterials as it is considered more eco-friendly and biocompatible [4]. Moreover, ZnO-NP can be synthesized from its saline precursors applying syntheses that do not involve hazardous chemicals or use high amounts of energy instead of the conventional procedures, which often show a high environmental impact [16].

In this context, the combination of organic nanoparticles, such as lignin nanoparticles (LNP) derived from biomass feedstock, with $\mathrm{ZnO}-\mathrm{NP}$ to realize nanohybrids can be a suitable strategy to obtain new interesting materials, which show the advantages of the distinct components [7]. In this sense, lignin and zinc oxide $(\mathrm{ZnO})$ hybrid systems represent an organic/inorganic combined nanomaterial, which shows unique structural and electronic properties [13]. Examples of the combined incorporation of lignin and metal oxides in different polymeric matrices can be found in [17-19], where the authors found effective results, due to the presence of the hybrids, in terms of enhanced antimicrobial, thermal, and mechanical behavior.

While lignin and $\mathrm{ZnO}-\mathrm{NP}$ have singly gained attention for numerous agricultural applications, hybrid systems of these materials have gained little attention. Nonetheless, some works have shown the possibility of using lignin nanoparticles to control the release of agrochemicals and fertilizers [20,21]. In particular, nanofertilizers have the advantage of providing specific nutrients, thus strongly limiting their dispersion into the environment. This characteristic allows nanofertilizers to be implemented in precision agriculture that avoids the unnecessary waste of substances compared to classical fertilizers [21]. The same conclusion can be extended to the use of herbicides and fungicides embedded in lignin nanoparticles, which reduces the risk of dispersion of these chemicals into the environment [22,23]. As for $\mathrm{ZnO}-\mathrm{NP}$, various positive effects have been found in crops when treated with this material at non-excessive doses [24]. In particular, in relation to the morphology and size of the particles, stimulatory effects on plant nutrition, biomass development, and antioxidant defenses have been recorded [24,25].

In view of the above, the first objective of the present work was the synthesis of a hybrid (ZnO@LNP) composed of lignin and zinc oxide, both in nanoparticle form and its characterization. Subsequently, the effect of the synthesized hybrid was evaluated on maize, which is a globally important crop chosen as a plant model in this study. In particular, the ZnO@LNP was tested on maize using seed-priming technology. Seed nano-priming 
is considered an effective treatment to induce changes in seed metabolism, positively influencing the early stages of plant development and the whole life cycle [26]. To the best of our knowledge, this is the first study that investigates the effect of a ZnO@LNP hybrid on the seed priming of a crop, exploiting the chemical and physical characteristics of the material, particularly its slow-release action. Furthermore, the application of this material directly to seeds avoids material waste or contains it strongly, making the nano-priming technology effective and sustainable.

\section{Materials and Methods}

\subsection{Synthesis of LNP, ZnO, and Hybrid ZnO@LNP}

LNP suspension was obtained from alkali lignin by hydrochloric acid treatment. Based on the procedures reported in the literature, $4 \%(w / v)$ of alkali lignin in ethylene glycol was maintained under stirring for $2 \mathrm{~h}$ at $35^{\circ} \mathrm{C}$ [11]. Afterwards, $\mathrm{HCl}(8 \mathrm{~mL}, 0.25 \mathrm{M})$ was mildly added to the solution at a rate of 3-4 drops $/ \mathrm{min}$. Then, the suspension was stirred for $2 \mathrm{~h}$ and filtered to eliminate soluble impurities from lignin. Afterwards, the solution was dialyzed against deionized water up to neutrality to obtain the LNP suspension.

$\mathrm{ZnO}-\mathrm{NP}$ have been synthetized by using a procedure already considered in [7]. In detail, $100 \mathrm{~mL}$ of $\mathrm{NaHCO}_{3} \quad 0.15 \mathrm{M}$ were dropped, under ultrasound irradiation for $1 \mathrm{~h}$ at $50 \%$ of amplitude at $70{ }^{\circ} \mathrm{C}$ and under argon flow, to $200 \mathrm{~mL}$ of a zinc acetate $0.1 \mathrm{M}$. The precipitate was centrifuged, washed, and calcined at $350{ }^{\circ} \mathrm{C}$ for $1 \mathrm{~h}$.

For the synthesis of hybrid materials, $250 \mathrm{~mL}$ of a mixture of lignin $(2.76 \mathrm{~g})$, zinc nitrate $(0.57 \mathrm{~g})$, and hexamethylenetetramine $(0.42 \mathrm{~g})$ was treated with high-power ultrasound for $45 \mathrm{~min}$ at $50 \%$ of amplitude at $90^{\circ} \mathrm{C}$ and under argon flow [7]. After the synthesis, the precipitate was centrifuged, washed, and dried. The high-power ultrasound irradiation was performed using an Ultrasonic processor VCX750 (Sonics \& Materials, Inc., Newton, CT, USA), $20 \mathrm{kHz}$, with a diameter tip of $13 \mathrm{~mm}$.

\subsection{Characterization of LNP and Hybrid ZnO@LNP}

Thermogravimetric measurements (TGA) of nanoparticle powders were performed under airflow $\left(50 \mathrm{~mL} \mathrm{~min}^{-1}\right)$ by using a Seiko Exstar 6300 (Seiko Instruments Inc., Chiba, Japan), applying a heating scan from 30 to $900{ }^{\circ} \mathrm{C}$ at $10^{\circ} \mathrm{C} \mathrm{min}^{-1}$.

Fourier infrared (FTIR) spectra of lignin nanoparticles, ZnO-NP and hybrid ZnO@LNP were recorded using a Jasco FTIR 615 spectrometer (Jasco Corporation, Tokyo, Japan) in the $4000-400 \mathrm{~cm}^{-1}$ range, in transmission mode. The materials were analyzed using $\mathrm{KBr}$ discs prepared by using pulverized natural materials and $\mathrm{KBr}$ powder.

The water contact angle of LNP and ZnO@LNP powders was also evaluated using the sessile drop method. Contact angles of the drops (FTA 1000, First Ten Angstroms, Newark, CA, USA) were measured at room temperature under static conditions on pressed disks of powdered materials; the measurement values represent the mean value of 10 drops. The analysis was estimated by measuring the angle of a $20 \mu \mathrm{L}$ deionized water sessile drop on the disc surfaces.

Lignin and $\mathrm{ZnO}$ hybrid nanoparticles were examined using a field emission scanning electron microscope (FESEM, Zeiss Supra 40, Dresden, Germany) at an operating voltage of $5 \mathrm{kV}$. Single drops of LNP and ZnO@LNP aqueous suspensions were cast onto a silicon substrate, dried for $24 \mathrm{~h}$, and gold sputtered before the analysis.

Elemental composition and chemical mapping were determined using a Bruker Quantax 200 ED (Bruker, Billerica, MA, USA).

TEM images were obtained using a Philips 208 Transmission Electron Microscope. (Philips, Eindhoven, The Netherlands). The samples were prepared by putting one drop of an ethanol dispersion of the catalyst powder on a copper grid pre-coated with a Formvar film and dried in air.

The XRD patterns were recorded with a Philips X'Pert PRO MPD diffractometer (Philips, Malvern, UK) operating at $40 \mathrm{kV}$ and $40 \mathrm{~mA}$, with a step of $0.03^{\circ}$ and a time per step of $30 \mathrm{~s}$ using $\mathrm{Cu} \mathrm{Ka}$ radiation and an $\mathrm{X}^{\prime}$ Celerator detector. 
The ICP analyses to determine $\mathrm{Zn}$ were performed by using a Varian 700-ES series (Varian, Santa Clara, CA, USA) inductively coupled plasma-optical emission spectrometer (ICP-OES) (Agilent Technologies, Santa Clara, CA, USA) on solutions prepared by dissolving the $\mathrm{ZnO} @ \mathrm{LNP}$ with $2 \mathrm{~mL}$ of $\mathrm{HNO}_{3} 65$ wt \% and $1 \mathrm{~mL}$ of $\mathrm{H}_{2} \mathrm{O}_{2} 35 \% v / v$ and adequately diluted.

\subsection{DPPH Activity of ZnO@LNP}

The antiradical activity of lignin and hybrid solutions was tested using a spectroscopic method, based on the disappearance of the absorption band at $517 \mathrm{~nm}$ of the free radical 2,2-diphenyl-1-picrylhydrazyl (DPPH) upon reduction by an antiradical compound. The test consisted of adding a certain amount of the aqueous solutions into $2 \mathrm{~mL}$ of a DPPH solution in methanol $\left(25 \mathrm{mg} \mathrm{mol}^{-1} \mathrm{~L}^{-1}\right)$ to have $50 \mathrm{mg} \mathrm{L}^{-1}$ as the concentration of the LNP solution in methanol. After that, the intensity of the $517 \mathrm{~nm}$ absorption band was measured by using an ultraviolet-visible (UV-Vis) spectrophotometer (Varian, Santa Clara, CA, USA). The antioxidant activity was expressed as the ability to scavenge the stable radical DPPH, which was calculated as radical scavenging activity (RSA) using the following equation (Equation (1)):

$$
(\mathrm{RSA}, \%)=\left[\left(\mathrm{A}_{\text {control }}-\mathrm{A}_{\text {sample }}\right) / \mathrm{A}_{\text {control }}\right] \times 100
$$

where $\mathrm{A}_{\text {control }}$ and $\mathrm{A}_{\text {sample }}$ are the absorbances of the control (methanol) at $\mathrm{t}=0 \mathrm{~min}$ and tested sample after $1 \mathrm{~h}$, respectively.

\subsection{In Vitro Release Profile of $\mathrm{Zn}$}

To quantify the release of $\mathrm{Zn}^{+2}, 100 \mathrm{mg}$ of $\mathrm{ZnO} @ \mathrm{LNP}$ were stirred in $100 \mathrm{~mL}$ of water at $\mathrm{pH}=7$ and $25^{\circ} \mathrm{C}$. After $1,4,8$, and $24 \mathrm{~h}, 5 \mathrm{~mL}$ of solution were taken, filtered, and analyzed by atomic absorption spectroscopy. The percentage of $\mathrm{Zn}^{+2}$ release was calculated as follows (Equation (2)):

$$
\mathrm{ZnR}=\frac{\text { Amount of released } \mathrm{Zn} \times 100}{\text { Total amount of } \mathrm{Zn} \text { in } \mathrm{ZnO} @ \mathrm{LNP}}
$$

\subsection{Seed Nano-Priming and Measurements}

Maize seeds (cv Belgrano) were sterilized with an aqueous solution of $\mathrm{NaClO}(0.25 \%$, $v / v$ ) for three minutes. Then, seeds were copiously washed with distilled water. To prime seeds, ZnO@LNP suspensions were sonicated for $5 \mathrm{~min}$ at the following concentrations, which was expressed as $\mathrm{ZnO}-\mathrm{NP}$ content in $\mathrm{mg}$ for liter:

$\checkmark \quad$ Control: only water

$\checkmark \quad \mathrm{T} 1: 8 \mathrm{mg}$ of $\mathrm{ZnO} @ L N P$ containing $0.32 \mathrm{mg}$ of $\mathrm{ZnO}$ in water at a final volume of $100 \mathrm{~mL}$ to reach a $\mathrm{ZnO}$ concentration of $3.2 \mathrm{mg} \mathrm{L}^{-1}$;

$\checkmark \quad \mathrm{T} 2: 32 \mathrm{mg}$ of $\mathrm{ZnO} @ \mathrm{LNP}$ containing $1.28 \mathrm{mg}$ of $\mathrm{ZnO}$ in water at a final volume of $100 \mathrm{~mL}$ to reach a $\mathrm{ZnO}$ concentration of $12.8 \mathrm{mg} \mathrm{L}^{-1}$;

$\checkmark \quad \mathrm{T} 3: 128 \mathrm{mg}$ of $\mathrm{ZnO} @ \mathrm{LNP}$ containing $1.28 \mathrm{mg}$ of $\mathrm{ZnO}$ in water at a final volume of $100 \mathrm{~mL}$ to reach a $\mathrm{ZnO}$ concentration of $51.2 \mathrm{mg} \mathrm{L}^{-1}$;

$\checkmark \quad \mathrm{T} 4: 512 \mathrm{mg}$ of $\mathrm{ZnO} @ \mathrm{LNP}$ containing $20.48 \mathrm{mg}$ of $\mathrm{ZnO}$ in water at a final volume of $100 \mathrm{~mL}$ to reach the concentration of $204.8 \mathrm{mg} \mathrm{L}^{-1}$;

$\checkmark \quad \mathrm{T} 5: 2.048 \mathrm{mg}$ of $\mathrm{ZnO} @ \mathrm{LNP}$ containing $81.92 \mathrm{mg}$ of $\mathrm{ZnO}$ in water at a final volume of $100 \mathrm{~mL}$ to reach the concentration of $819.2 \mathrm{mg} \mathrm{L}^{-1}$.

Then, seeds were immersed in $10 \mathrm{~mL}$ of these solutions and maintained for $24 \mathrm{~h}$ under slow stirring. Afterwards, seeds were placed on paper in Petri dishes (10 seeds/plate), added with $10 \mathrm{~mL}$ of distilled water, and maintained in the dark $(24 \pm 2){ }^{\circ} \mathrm{C}$. The number of germinated seeds, and their radicle length, were recorded at 4 and 5 days after priming, 
respectively. The germination index was estimated according to Navarro-López et al. [27], using the following equation (Equation (3)):

$$
\mathrm{GI}=(\mathrm{G} \times \mathrm{L}) /(\mathrm{Gw} \times \mathrm{Lw})
$$

where $G$ and $L$ are the germination and radicle length $G$ and $L$ recorded for a specific treatment, and Gw and Lw are the values recorded for control seeds.

The relative seed germination (RSG) was estimated in primed seeds, using the following equation (Equation (4)) [27]:

$$
\mathrm{SG}=\frac{\text { Seeds germinated in the treating solutions }}{\text { Num of seeds germinated in water }} \times 100 \text {. }
$$

\subsection{Plant Materials and Growth Conditions}

Five days after priming, young maize seedlings, controls, and those treated with T1, $\mathrm{T} 2, \mathrm{~T} 3$, and $\mathrm{T} 4$ were transferred into hydroponic solutions ( 24 total seedlings per treatment distributed in 3 trays in order to have three replications). Seeds primed with T5 were excluded due to the clear toxicity exerted by this treatment (Table 1 ). Then, the samples were grown according to a published procedure [28] in a nutrient solution consisting of $2 \mathrm{mM} \mathrm{Ca}\left(\mathrm{NO}_{3}\right)_{2} \bullet 4 \mathrm{H}_{2} \mathrm{O}, 0.5 \mathrm{mM} \mathrm{MgSO}_{4} \bullet 7 \mathrm{H}_{2} \mathrm{O}, 0.7 \mathrm{mM} \mathrm{K}_{2} \mathrm{SO}_{4}, 0.1 \mathrm{mM} \mathrm{KCl}, 0.1 \mathrm{mM}$ $\mathrm{KH}_{2} \mathrm{PO}_{4}, 1 \mu \mathrm{M} \mathrm{H}_{3} \mathrm{BO}_{3}, 0.5 \mu \mathrm{M} \mathrm{MnSO}_{4} \bullet \mathrm{H}_{2} \mathrm{O}, 0.5 \mu \mathrm{M} \mathrm{CuSO}_{4}, 0.5 \mu \mathrm{M} \mathrm{ZnSO}{ }_{4} \cdot 7 \mathrm{H}_{2} \mathrm{O}$, $0.01 \mu \mathrm{M}\left(\mathrm{NH}_{4}\right)_{6} \mathrm{Mo}_{7} \mathrm{O}_{24} \bullet 4 \mathrm{H}_{2} \mathrm{O}$, and $100 \mu \mathrm{M}$ Fe-EDTA. Seedlings were maintained at $(24 \pm 2){ }^{\circ} \mathrm{C}$ and light intensity of $150 \mu \mathrm{mol} \mathrm{m}{ }^{-2} \mathrm{~s}^{-1}$ (photoperiod: $12 / 12 \mathrm{~h}$ ). After 14 days (second fully developed foliar stage), the plants' shoot and root length and fresh weight were recorded. Then, the proper amount of plant material was harvested and submitted to the following analyses.

Table 1. Effect of the treatments with ZnO@LNP on germination, radicle length, relative seed germination (RSG), and germination index (GI) of maize compared to the untreated controls (T1, T2, $\mathrm{T} 3$, T4, and $\mathrm{T} 5$ refer to $\mathrm{ZnO}-\mathrm{LNP}$ concentration used for seed nano-priming).

\begin{tabular}{ccccc}
\hline & Germination & RSG & Radicle Length & GI \\
\hline & $\mathbf{( \% )}$ & $\mathbf{( \% )}$ & $\mathbf{( c m )}$ & $\mathbf{( \% )}$ \\
\hline Control & $77 \pm 5^{\mathrm{b}}$ & - & $2.10 \pm 0.30^{\mathrm{b}}$ & - \\
T1 & $83 \pm 10^{\mathrm{ab}}$ & $109 \pm 7^{\mathrm{b}}$ & $2.56 \pm 0.50^{\mathrm{ab}}$ & $133 \pm 9^{\mathrm{c}}$ \\
T2 & $97 \pm 10^{\mathrm{a}}$ & $126 \pm 2^{\mathrm{a}}$ & $2.83 \pm 0.28^{\mathrm{a}}$ & $170 \pm 3^{\mathrm{a}}$ \\
T3 & $93 \pm 6^{\mathrm{a}}$ & $122 \pm 5^{\mathrm{a}}$ & $2.80 \pm 0.27^{\mathrm{a}}$ & $165 \pm 6^{\mathrm{a}}$ \\
T4 & $87 \pm 8^{\mathrm{ab}}$ & $113 \pm 1^{\mathrm{b}}$ & $2.81 \pm 0.25^{\mathrm{a}}$ & $151 \pm 2^{\mathrm{b}}$ \\
T5 & $56 \pm 5^{\mathrm{c}}$ & $54 \pm 10^{\mathrm{c}}$ & $1.67 \pm 0.40^{\mathrm{b}}$ & $49 \pm 9^{\mathrm{d}}$ \\
\hline
\end{tabular}

In each column and for each parameter, mean values followed by different letters are significantly different $(p<0.05)$.

\subsection{Estimation of Chlorophyll a and b, Carotenoid, Anthocyanin, Total Phenols, DPPH, MDA}

Chlorophyll $\mathrm{a}$ and $\mathrm{b}$ and carotenoids were assessed in maize seedlings collected 14 days after the priming. First, $1.0 \mathrm{~g}$ of leaf samples were extracted with $85 \%$ acetone in water $(v / v)$, with a pestle in a mortar using quartz sand. Then, the suspension was filtered, and the absorbance was recorded at $452.5,644$, and $663 \mathrm{~nm}$ to obtain chlorophyll a and b as well as the carotenoid contents [29]. In addition, the total chlorophylls concentration (Chl $\mathrm{a}+\mathrm{Chl} \mathrm{b}$ ) was estimated as the sum of $\mathrm{Chl}$ a and $\mathrm{Chl} b$, while the relative ratio of these pigments was as expressed as $\mathrm{Chl} a / \mathrm{Chl} b$.

As for anthocyanin determination, $0.5 \mathrm{~g}$ of fresh maize shoots were collected and extracted with ethanol (95\%). The resulting suspension was centrifuged at $5000 \mathrm{rpm}$ for $20 \mathrm{~min}$. The anthocyanin content was determined at 535 and $650 \mathrm{~nm}$ [30].

First, $1.0 \mathrm{~g}$ of fresh maize shoots were extracted with $10 \mathrm{~mL}$ of methanol and left to stir at room temperature overnight to determine the TP and DPPH contents [31]. Afterwards, 
the suspension was centrifuged at $7000 \mathrm{rpm}$ for $20 \mathrm{~min}$, and the supernatant was filtered. The TP content was determined by adding $0.5 \mathrm{~mL}$ of the extracts to $7 \mathrm{~mL}$ of distilled water and $0.5 \mathrm{~mL}$ of Folin-Ciocalteu's phenol reagent. After $5 \mathrm{~min}, 2 \mathrm{~mL}$ of $2 \%$ sodium carbonate $(w / v)$ were added to this solution, which was incubated at room temperature for $2 \mathrm{~h}$. Finally, the absorbance was read at $750 \mathrm{~nm}$ reporting the TP as $\mathrm{mg}$ of gallic acid equivalent (GAE) $\mathrm{g}^{-1}$ per dry weight (DW) [31].

The antioxidant activity of the methanolic plant extracts, obtained as described above, was assessed toward the DPPH. First, $0.5 \mathrm{~mL}$ of the methanolic extract was added to this scope with $1 \mathrm{~mL}$ of ethanol and $1 \mathrm{~mL}$ of a solution $0.101 \mathrm{mM}$ of DPPH. Then, the solution so obtained was left to react for $10 \mathrm{~min}$ at room temperature. Subsequently, the absorbance was recorded at $517 \mathrm{~nm}$, and the scavenge ability of the extract toward the DPPH was calculated as RSA, as indicated in Section 2.2.

The MDA content was determined in maize subjected to the various treatments and collected 14 days after priming. To this end, $0.5 \mathrm{~g}$ of fresh shoot tissue was homogenized with $5 \%(w / v)$ trichloroacetic, and the resulting suspension was centrifuged at $5000 \mathrm{rpm}$ for $15 \mathrm{~min}$. Then, the supernatant was added to $0.5 \mathrm{~mL}$ of $0.25 \%(w / v)$ thiobarbituric and heated at $95{ }^{\circ} \mathrm{C}$ for $20 \mathrm{~min}$. After quick cooling, the MDA content was quantified spectrophotometrically [28].

\subsection{Statistical Analysis}

Each value reported is the mean of the data from three independent experiments on at least three biological replicates per experiment. Statistical analysis of the data was performed in ANOVA mode by examining the variance with Duncan's test at $p<0.05$. The $R$ statistical environment was used to conduct the statistical analysis.

\section{Results}

\subsection{ZnO@LNP Characterization}

TGA analysis for the two prepared nanoparticles was performed, and the results of their thermal degradation behavior in the air are reported in Figure 1a. The technique was also used to determine the amount of $\mathrm{ZnO}$ on the surface of the hybrid lignin nanoparticles. The results confirmed that lignin decomposition started by water release, which was followed by the first decomposition step between 200 and $300{ }^{\circ} \mathrm{C}$, which led to the formation of low molecular weight products due to propanoid's side-chain cleavage. The main decomposition step occurred at higher temperatures $\left(300-450{ }^{\circ} \mathrm{C}\right)$, with the cleavage of the main lignin chain, and was followed (above $500{ }^{\circ} \mathrm{C}$ ) by several rearrangements and condensation reactions of the aromatic structure that leads to the formation of char structures [32,33]. The degradative path of ZnO@LNP was similar, with a slight shift toward higher temperature for the initial degradation events, a lower degradation rate related to the main, but a lower peak temperature $\left(400\right.$ and $413{ }^{\circ} \mathrm{C}$, respectively for ZnO@LNP and LNP), which was essentially related to the catalytic role of $\mathrm{ZnO}-\mathrm{NP}$ nanoparticles at high temperature [34]. The degradation in the oxidative environment (not shown here) confirmed that $4 \mathrm{wt} \%$ of $\mathrm{ZnO}$ was found on the LNP surface.

FTIR analysis of LNP, ZnO-NP, and ZnO@LNP was also conducted. The analysis results, reported in Figure 1b, showed that in the case of LNP, the typical signals of the nanoscaled lignin already observed in previous investigations were found [11]. In detail, a broad band at 3600-3300 $\mathrm{cm}^{-1}$, corresponding to hydroxyl groups in phenolic and carboxylic acids and bands around 2936 and $2840 \mathrm{~cm}^{-1}$, attributed to C-H stretch present in methyl, methylene, and methoxyl groups, were found. Signals at 1512 and $1421 \mathrm{~cm}^{-1}$, attributed to the aromatic ring vibrations of phenylpropanoid (C9) skeleton of lignin and bands detected at 1270 and $812 \mathrm{~cm}^{-1}$, corresponding to $\mathrm{C}=\mathrm{O}$ stretch in guaiacyl unit and C-H out-of-plane vibrations in 2, 5, and 6 positions of guaiacyl units, were also identified. Furthermore, the spectrum of LNP shows intensity bands at $1216 \mathrm{~cm}^{-1}$ (C-C, C-O, and $\mathrm{C}=\mathrm{O}$ stretching), $1120 \mathrm{~cm}^{-1}$ and $1082 \mathrm{~cm}^{-1}$, assigned, respectively, to condensed aromatic units and $\mathrm{C}-\mathrm{O}$ stretch of secondary alcohols and aliphatic ethers. In the case of $\mathrm{ZnO}$, the 
peaks observed at 3323, 1453, 1380, 1336, 1056, and $1017 \mathrm{~cm}^{-1}$ are due to the $\mathrm{O}-\mathrm{H}$ stretching and bending vibrations of adsorbed water molecules [35]. Additionally, peaks at 1730, 1660 , and $1532 \mathrm{~cm}^{-1}$ can be identified with the presence of $\mathrm{CO}_{2}$. The absorption peak associated with the $\mathrm{Zn}-\mathrm{O}$ stretching band appears clearly at 500 and $702 \mathrm{~cm}^{-1}$, confirming the formation of $\mathrm{ZnO}-\mathrm{NPs}$ [36]. The peaks at 530 and $411 \mathrm{~cm}^{-1}$ can also be assigned to the metal oxygen (M-O) stretching mode [37]. Comparison of the obtained spectra for LNP and ZnO@LNP showed that a reduction of $\mathrm{OH}$ stretching can be found at higher wavenumbers, while shifting of bands at 2927, 2918, and $2849 \mathrm{~cm}^{-1}$, that represent C-H stretching, and 1451 and $1384 \mathrm{~cm}^{-1}$ (ascribed to the in-plane bending vibrations of the $\mathrm{CH}_{2}$ groups) were noted. The signal of C-C stretching of aromatic skeletal at $1540 \mathrm{~cm}^{-1}$ was also more visible in ZnO@LNP. Narrow peaks appeared near 464, 478, and $505 \mathrm{~cm}^{-1}$ represent transverse optical stretching vibrations of $\mathrm{Zn}-\mathrm{O}$, confirming the presence of zinc oxide nanoparticles, and these observations were well consistent with other reports [38]. The reduced wettability in the presence of $\mathrm{ZnO}$ was also confirmed by the results of water contact angle measurements, as reported in Figure 1c,d. Mean values of 59 and $57^{\circ}$ were registered, respectively, for LNP and ZnO@LNP, supporting the changes in surface hydrophilicity for the lignin nanoparticles in the presence of hydrophobic zinc oxide. Variation in surface wettability could also be due to different porosities and roughness of the material.

\section{TGA}

a)

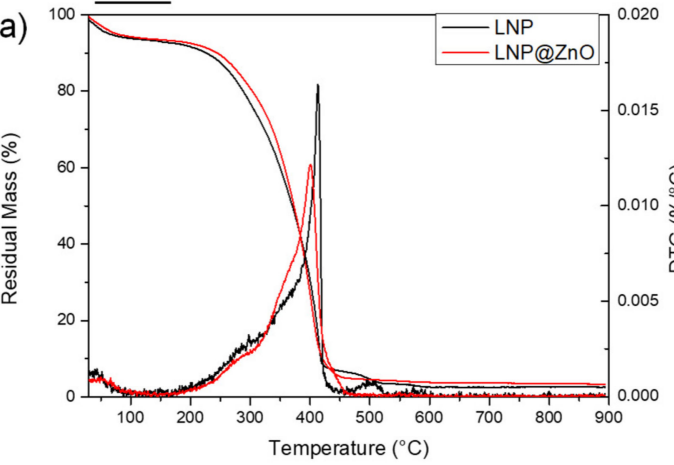

WCA

c)

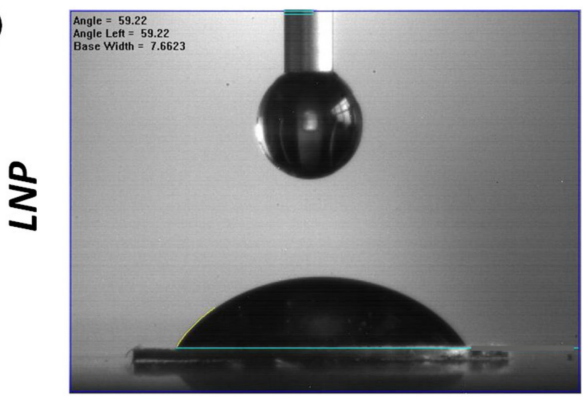

\section{FT-IR}

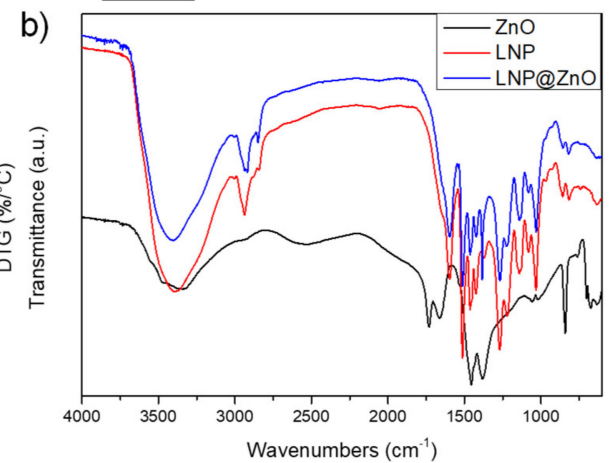

d)

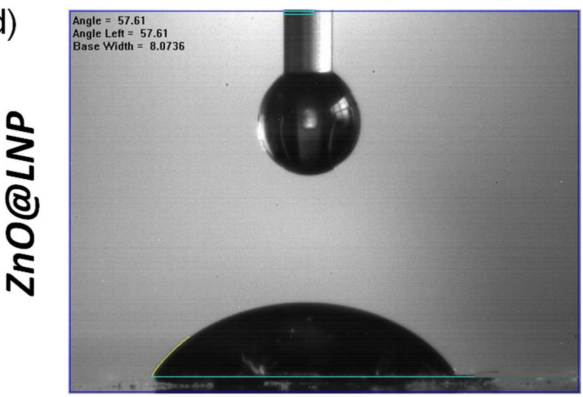

Figure 1. TG/DTG curves of LNP and ZnO@LNP in air (a), FTIR spectra of LNP, ZnO, and ZnO@LNP (b), water contact angle images for LNP and ZnO@LNP (c,d).

As shown in Figure 2a, FESEM images of LNP, ZnO, and ZnO@LNP at high magnifications confirmed that the ZnO@LNP sample consists of uniformly dispersed nanosized particles of zinc oxide, with more or less spherical morphology, "encapsulated" on the cavities provided by the macromolecular matrix lignin [39]. The TEM images (Figure 2b) confirm the SEM analyses. 

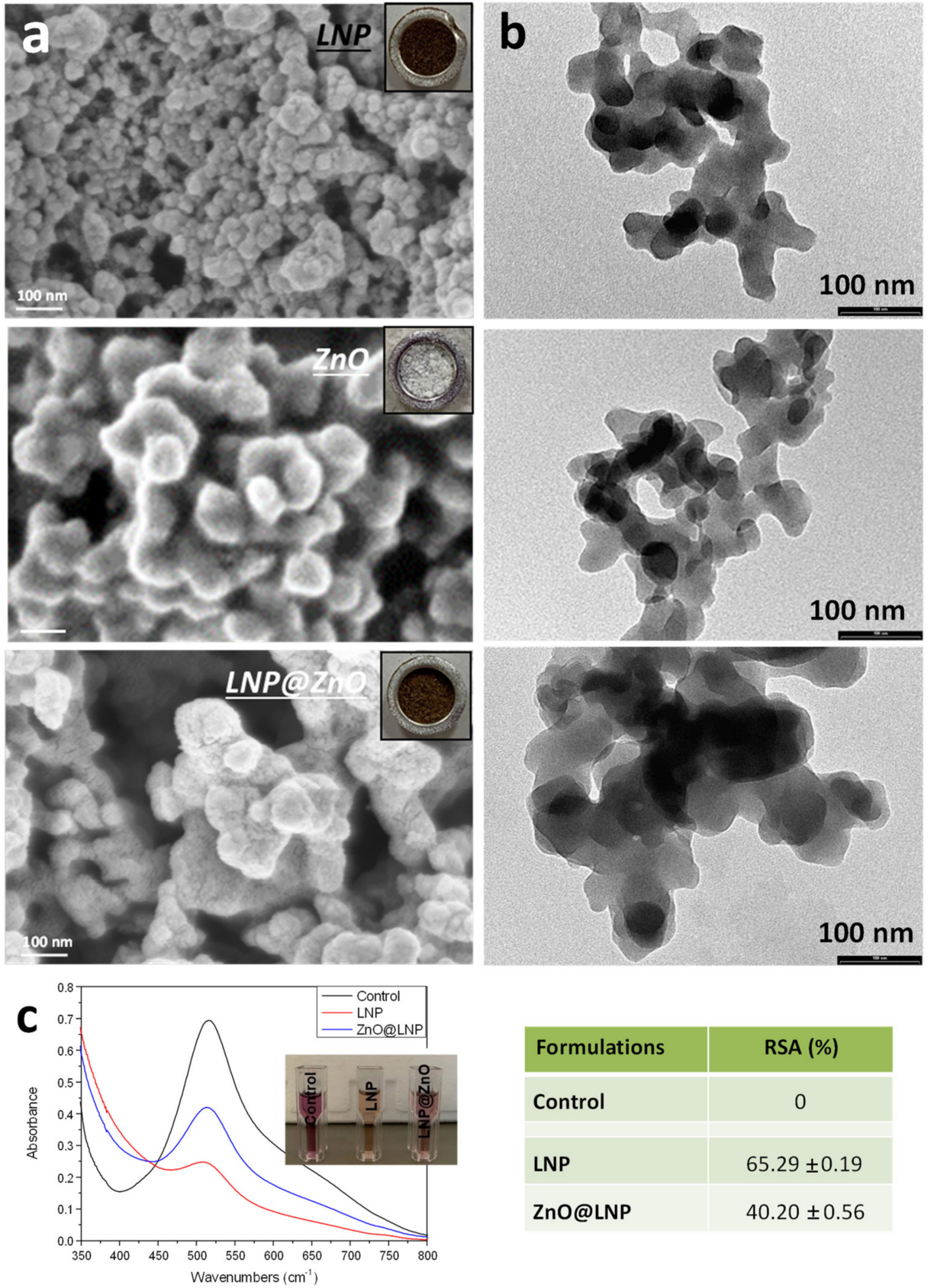

\begin{tabular}{|l|c|}
\hline Formulations & RSA (\%) \\
\hline Control & 0 \\
\hline LNP & $65.29 \pm 0.19$ \\
\hline ZnO@LNP & $40.20 \pm 0.56$ \\
\hline
\end{tabular}

Figure 2. FESEM (a) and TEM (b) images of LNP, ZnO, and ZnO@LNP (the inset images show the color change due to the formation of lignin-derived $\mathrm{ZnO}$ ), UV spectra (c) and RSA results for LNP and ZnO@LNP.

The presence of phenolic groups even on ZnO@LNP (as revealed by FTIR spectroscopy) motivated us to explore their antioxidant potential further. The results of DPPH scavenging activity for pristine LNP and ZnO@LNP systems are reported in Figure 2c. Compared to the control, the absorbance band at $517 \mathrm{~nm}$ decreased, while the DPPH scavenging activity increased up to $65.3 \%$ after $1 \mathrm{~h}$ of incubation for LNP. As widely reported in the literature [10], the antioxidant activity of lignin is determined by the high number of phenolic moieties, which undergo a proton-coupled electron transfer mechanism. Meanwhile, considering the high specific surface area and small spherical lignin nanoparticle size, all of these factors contribute to higher proton capability for the phenyl group of lignin. When $\mathrm{ZnO}$ was considered, a sensible reduction in RSA values (40.2\%) was measured, suggesting that some phenolic groups were linked to lignin by hydrogen bonds, as confirmed by the 
shifting for a few bands in FTIR analysis, or they were oxidized during the preparation of the hybrid, which can explain the loss of antioxidant power [40]. The antioxidant property of ZnO@LNP may also be due to a superposition with the electron donation property of oxygen atom in $\mathrm{ZnO}$ nanomaterial, as already reported in previous studies [39].

EDX analyses were performed to verify the homogeneous dispersion of $\mathrm{Zn}$ on the LNP surface (Figure 3a-c), while XRD analysis (Figure 3d) showed the characteristic reflection peaks of $\mathrm{ZnO}: 2 \theta$ at $31.8^{\circ}, 34.4^{\circ}, 36.3^{\circ}, 47.5^{\circ}, 56.7^{\circ}, 62.8^{\circ}, 64.4^{\circ}, 67.9^{\circ}$, and $69^{\circ}$ (JPCDS 01-079-2205).
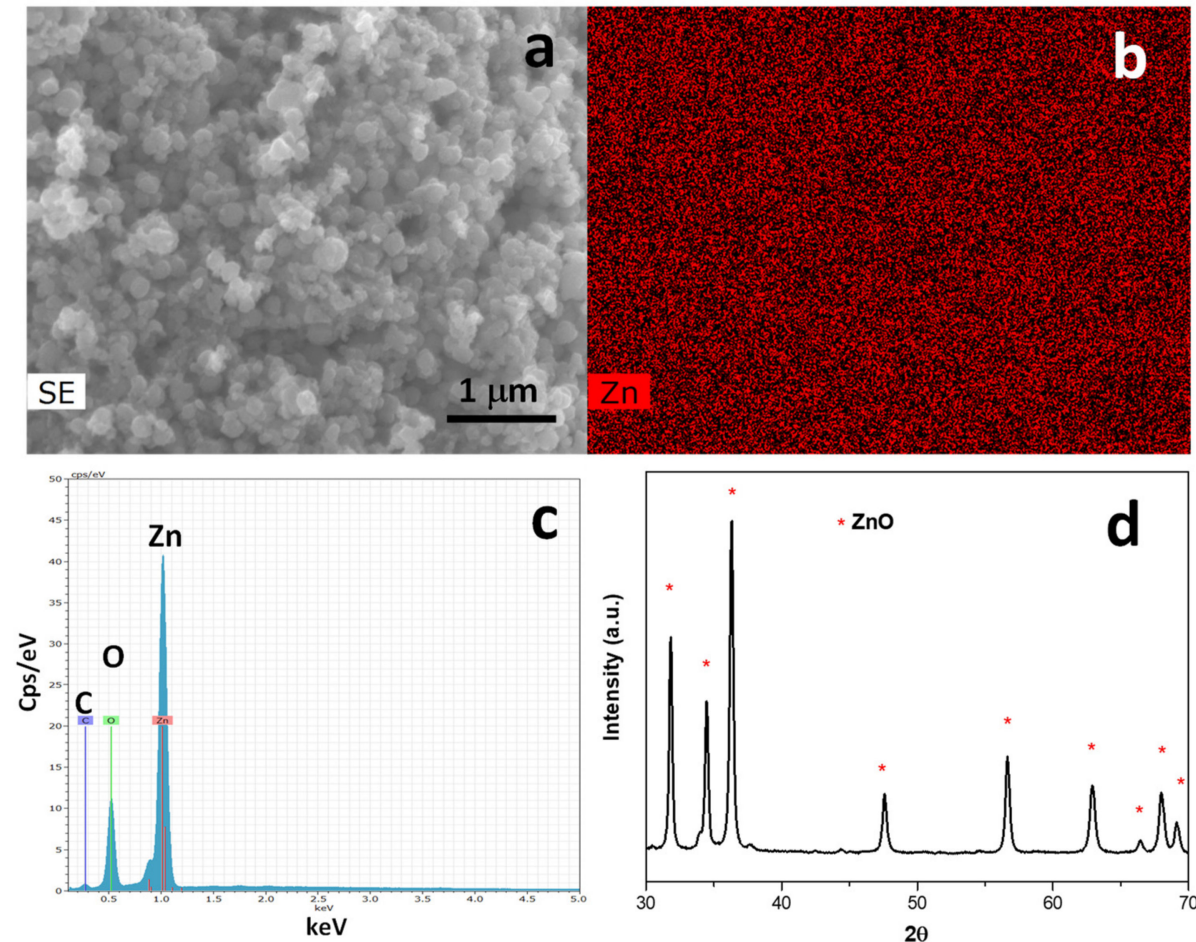

Figure 3. SEM image of the area analyzed by EDX (a), elemental mapping of Zn (b), EDX spectrum (c), and XRD (d) of ZnO@LNP.

The release profile of $\mathrm{Zn}^{+2}$ (Figure 4 ) shows that after $1 \mathrm{~h}$, the percentage of $\mathrm{Zn}$ released in solution was $3.3 \%$, and as the time increased, after $24 \mathrm{~h}$, it reached the value of about $6.5 \%$. The release test highlighted the material's ability to slow-release $\mathrm{Zn}^{+2}$ over time, and this phenomenon could demonstrate the ability of the ZnO@LNP to release zinc when in contact with maize seeds. Therefore, such an effect can evidence the hybrid's capacity to stimulate the growth and development of the plant.

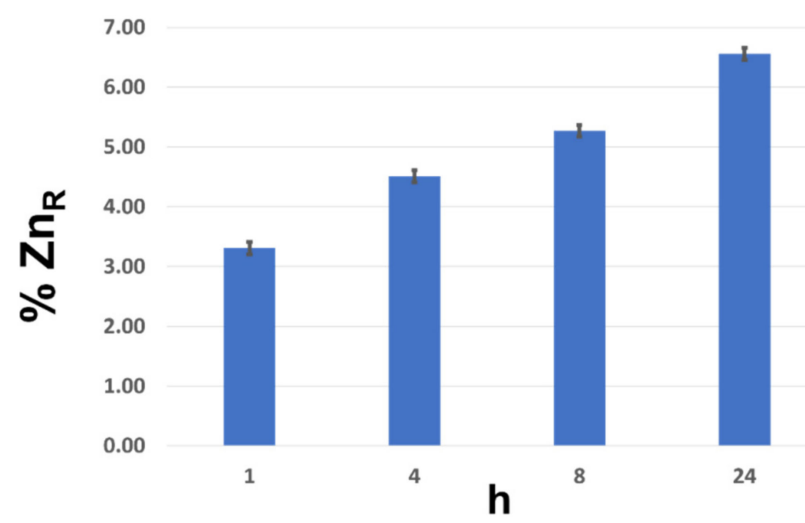

Figure 4. In vitro release profile of $\mathrm{Zn}^{+2}$ by $\mathrm{ZnO@LNP.}$ 


\subsection{Effect of ZnO@LNP on Seed Development and Maize Growth}

The nano-priming with ZnO@LNP affected seed germination, radicle length, RSG, and GI (Table 1). In particular, T2 and T3 stimulated the seed germination significantly compared to control seeds. The other treatments did not influence this parameter, except for T5, which depressed the capacity of seeds to germinate. Data of relative seed germination (RSG) revealed that T2 and T3 significantly impacted this parameter. The germination represents a critical phase in plant development, and effective seed priming has been reported to positively affect seed metabolism and promote numerous signaling pathways, thus improving seedlings establishment and the entire lifecycle of the primed plants [26]. Some nanomaterials can positively affect seed development if the dosage applied does not reach phytotoxic levels. Furthermore, seed nano-priming could stimulate the expression of many genes during germination, especially those related to plant stress tolerance [41,42]. This last aspect is crucial, as improving plant tolerance to abiotic and biotic stress through seed priming could be strategic for crop protection [42]. Seed germination is mainly regulated by signals that include the controlled production of reactive oxygen species (ROS), resulting in improved water absorption and cell extension [43]. In this context, zinc is involved in the controlled production of ROS and the activation of NADPH oxidase, $\alpha$-amylase, and protease. Furthermore, $\mathrm{Zn}$ can induce the production of secondary metabolites, which can positively affect the first stage of seeds' development [44,45]. In particular, seed attributes can be improved by $\mathrm{ZnO}-\mathrm{NP}$ for its electronic characteristics, which can give rise to the photosensitization and photogeneration of ROS [46]. Consequently, this improves oxygen imbibition and water absorption by seeds, thus allowing faster and ameliorated seed germination [47]. Despite this, excessive concentrations of nanomaterials can hamper seed metabolism and development and consequently plant growth, thus generating a plethora of phytotoxic effects in plants [48,49]. For this, the controlled release of $\mathrm{ZnO}-\mathrm{NP}$ through nanocarrier delivery appears to be a strategic approach to avoid an immediate exposure of seeds to excessive concentrations of this oxide [44]. The use of lignin nanoparticles as a nanocarrier for the controlled release of $\mathrm{ZnO}-\mathrm{NP}$ could permit the achievement of noteworthy results on seed development without exerting toxicity on a wide range of concentrations. Moreover, it should be considered that lignin is a biocompatible polymer that is relatively biodegradable, which makes its use safe. In addition, lignin itself is known to promote beneficial effects on plant growth as it can influence the hormonal status and the development of seeds [11].

Radicle length, recorded five days after the treatments, revealed that the nano-priming generally stimulated radicle length, while T5 was the only phytotoxic treatment. Furthermore, the germination index (GI), which combines the effects of the priming solution on seed and radicle length (for this measure, the control is considered as $100 \%$ ), revealed that the treatment positively affected this parameter, even though to a different extent, with the only exception of T5. Zinc regulates hormone metabolism, which controls the first phases of seed and radicle development by affecting the auxin levels [47]. This effect occurs thanks to the ability of this zinc to modulate the tryptophan biosynthesis [47]. In general, it has been found that depending on the treated species, $\mathrm{ZnO}-\mathrm{NP}$ can result in different effects on radicle elongation, also causing severe toxic effects [50]. Nonetheless, hybrid nanoparticles can positively affect germination and root length, and this action has been explained on the efficacy of the nanosystems to allow easier penetration of the seed coat and increase the number of holes [26]. Such an effect may also result in increased oxygen transfer to seeds and water uptake efficiency [51,52].

\subsection{Effect of ZnO@LNP on Plant Growth}

Since the results obtained from the above determinations showed that T5 was phytotoxic to maize, this treatment was not further included in the subsequent determinations (Table 1). As far as shoot length is concerned, T3 and T4 increased this parameter in nano-primed maize, while the other treatments did not show any effect (Figure 5). Differently, all the ZnO@LNP concentrations applied did not affect root length (Figure 5). 
The shoot fresh weight was stimulated by T2, T3, and T4, whilst T1 did not affect maize compared to control samples. As for root fresh weight, all the treatments stimulated this trait on treated plants, with T4 showing a remarkable effect. Priming with nanomaterials may also benefit seedlings by stimulating plant growth and defensive mechanisms, which were mainly related to increased antioxidant properties [46]. The mechanism by which $\mathrm{ZnO}-\mathrm{NP}$ activates these processes is still largely unknown and under debate; however, several studies have shown that this material can improve the performance of the treated species at low dosages, increasing root and shoot biomass [46]. The effect of ZnO-NPs, in addition to the concentrations applied, was related to the mode of its application. In particular, direct administration to the growth medium in developing plants can decrease their growth due to rapid dissolution of the oxide in $\mathrm{Zn}^{2+}$, which could alter already at low concentrations root epidermis, thus compromising the entire functionality of the root organs $[24,53]$. Nonetheless, it has been shown that nanoparticle systems, in general, can activate the expression of genes involved in nutrient transport in plants [24]. Moreover, it should be noted that the use of nanocarriers has the advantage of allowing a controlled release of zinc oxide, significantly reducing its toxicity and maximizing its benefits [44].
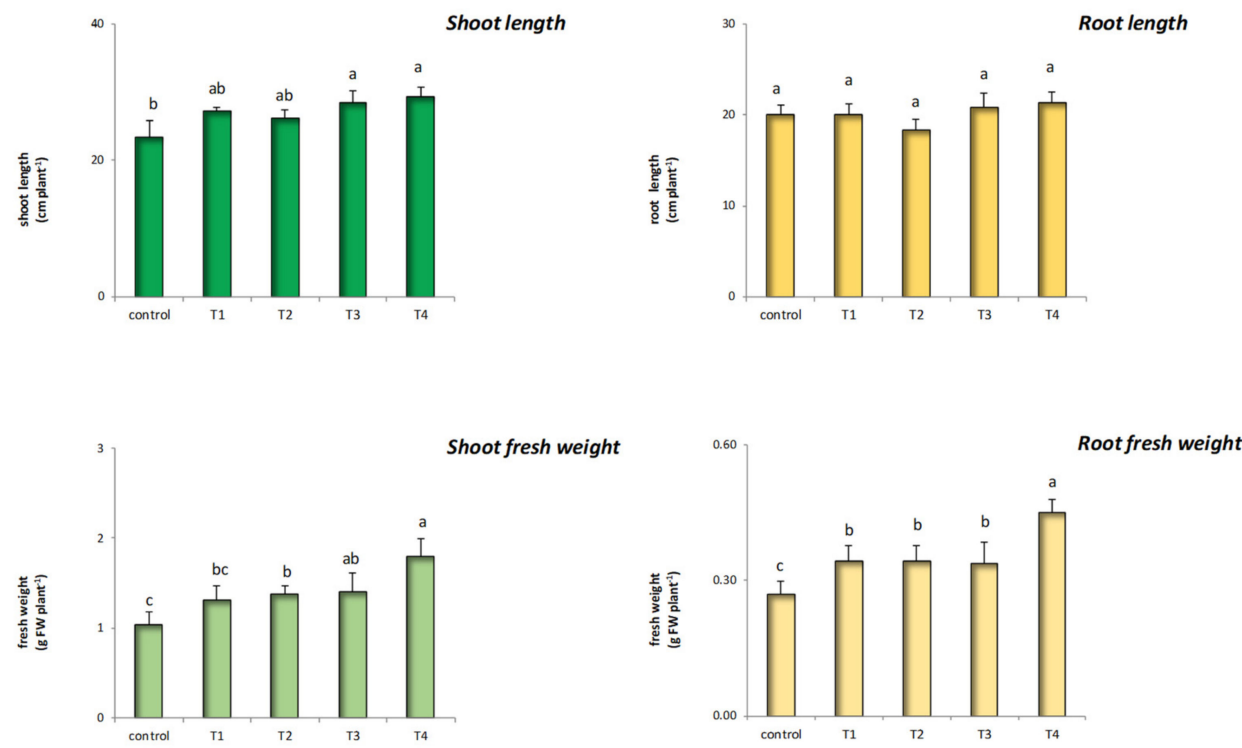

Figure 5. Effect of the treatments with ZnO@LNP on the shoot and root length and fresh weight compared to the untreated controls (T1, T2, T3, T4, and T5 refer to the ZnO@LNP concentration used for seed nano-priming). Letters in the figure, if different, indicate statistically significant differences for $p<0.05$ between treatments.

\subsection{Effect of ZnO@LNP on Pigment and Soluble Protein}

Some other aspects of nano-primed plants were investigated, and they are shown in Table 2. In particular, the content of chlorophyll $a$ and $b$ (Chl a and $\mathrm{Chl} b$ ), the sum $(\mathrm{Chl} \mathrm{a}+\mathrm{Chl} \mathrm{b})$, the ratio $\mathrm{Chl} \mathrm{a/Chl} \mathrm{b}$, and the carotenoid content showed trends generally in agreement with each other. As for $\mathrm{Chl}$ a, the treatments T2, T3, and T4 affected the pigment content in nano-primed maize, while $\mathrm{T} 1 \mathrm{did}$ not. Concerning $\mathrm{Chl} b$, none of the treatments applied modified its content. Regarding the sum of Chl a and Chl b, T2, T3, and T4 determined a significant increase in the total amount of chlorophylls. Some work showed that nanomaterials, mainly metal oxide nanoparticles, can affect the content of chlorophyll $\mathrm{a}$ and $\mathrm{b}$, also in abiotic stress conditions such as salinity and heavy metals contamination [54-57]. Zinc participates in chlorophyll synthesis, being involved in protochlorophyllide formation and chloroplast development [46]. This biochemical aspect is relevant, since the effect of ZnO@LNP resulted in significant increases in chlorophyll a and total chlorophyll. This stimulation reveals that ZnO@LNP treatments may prompt higher photosynthetic activity, resulting in increases in plant biomass production, justifying 
the data obtained in this study (Figure 5). In addition, increases in chlorophyll a are associated with the physiological adaptation of plants to external stimuli aimed to increase the plant's capacity to harvest light [57]. The ratio $\mathrm{Chl} \mathrm{a/Chl} \mathrm{b,} \mathrm{usually} \mathrm{around} \mathrm{3,} \mathrm{can}$ be predictive of the amount of chlorophyll associated with the photosystems, and, also, it is used to estimate plant responses to environmental changes and stress or external stimuli [58]. Our experiments showed significant increases in this ratio only in the case of $\mathrm{T} 2$ and T3. This effect is worth mentioning, as the chlorophyll-protein complex, which has the function to harvest light, is positively related to the activity of photosystem II (PSII) [58]. Therefore, the results show that ZnO@LNP can be a valuable tool to stimulate the content of chlorophyll a and the activity of PSII.

Table 2. Effects of the nano-priming treatments with different concentrations of ZnO@LNP on the content of chlorophylls a and b, their sum and relative ratio, carotenoids, and soluble protein (T1, T2, T3, T4, and T5 refer to ZnO@LNP concentration used for seed nano-priming).

\begin{tabular}{|c|c|c|c|c|c|}
\hline & Chl a & Chl b & Chl $a+C h l b$ & Chl a/Chl b & Carotenoids \\
\hline & $\left(\mathrm{mg} \mathrm{g}^{-1} \mathrm{FW}\right)$ & $\left(\mathrm{mg} \mathrm{g}^{-1} \mathrm{FW}\right)$ & $\left(\mathrm{mg} \mathrm{g}^{-1} \mathrm{FW}\right)$ & & $\left(\mathrm{mg} \mathrm{g}^{-1} \mathrm{FW}\right)$ \\
\hline Control & $3.88 \pm 0.30^{b}$ & $1.16 \pm 0.05^{b}$ & $5.04 \pm 0.28^{b}$ & $3.34 \pm 0.34^{b}$ & $0.35 \pm 0.02^{b}$ \\
\hline $\mathrm{T} 1$ & $3.99 \pm 0.22^{b}$ & $1.09 \pm 0.14^{b}$ & $5.08 \pm 0.35^{b}$ & $3.66 \pm 0.30^{\mathrm{ab}}$ & $0.33 \pm 0.04^{b}$ \\
\hline $\mathrm{T} 2$ & $4.62 \pm 0.24^{a}$ & $1.19 \pm 0.06^{b}$ & $5.81 \pm 0.31^{\mathrm{a}}$ & $3.88 \pm 0.11^{\mathrm{a}}$ & $0.41 \pm 0.03^{a}$ \\
\hline $\mathrm{T} 3$ & $4.86 \pm 0.41^{\mathrm{a}}$ & $1.17 \pm 0.22^{b}$ & $6.03 \pm 0.50^{a}$ & $4.15 \pm 0.61^{\mathrm{a}}$ & $0.44 \pm 0.01^{a}$ \\
\hline $\mathrm{T} 4$ & $4.63 \pm 0.28^{a}$ & $1.26 \pm 0.28^{b}$ & $5.89 \pm 0.32^{a}$ & $3.67 \pm 0.11^{b}$ & $0.41 \pm 0.03^{a}$ \\
\hline
\end{tabular}

In each column and for each parameter, mean values followed by different letters are significantly different $(p<0.05)$.

The carotenoid content increased in response to T2, T3, and T4, while T1 did not affect this parameter. Carotenoids are essential light-harvesting pigments with protective functions. They show antioxidant properties and operate in removing ROS, thus protecting chloroplast from oxidative stress that biotic and abiotic stresses could cause [59]. In addition, carotenoids operate in quenching chlorophyll in triplet or singlet form [46]. Carotenoids are gaining increasing interest for their nutraceutical value as bioactive and health-promoting compounds, and there is intense research toward strategies that can raise the content of molecules with known nutraceutical value [60]. As mentioned above, zinc can stimulate the activity of NADH oxidase and the formation of ROS, and this effect persists during the later stages of development of the treated plant $[44,45]$. Therefore, the plant response associated with the treatment with ZnO@LNP was that of elevating the content of this beneficial and pivotal class of protective pigment, as evidenced by other studies $[46,61]$.

\subsection{Effect of ZnO@LNP on Antioxidants and Oxidative Status of Nano-Primed Maize Seedlings}

Some determinations have been conducted on seeds nano-primed with ZnO@LNP to evidence any eventual effect on the nanomaterial on the antioxidant and oxidative status of seedlings collected 14 days after the treatments (Table 3). T2, T3, and T4 generally elevated the anthocyanin and TP content compared to control samples, while T1 was unable to exert an inductive effect on the above parameters.

Many different secondary metabolites show scavenging activities against free radical and antioxidant properties, and their content in plants can be modulated in response to environmental factors [62]. In particular, anthocyanins have a protective function in the vacuole by inhibiting or containing the lipid peroxidation, and their production could increase as a photo-protection to avoid photo-oxidative injuries [46]. Phenols have been documented to increase the following abiotic stresses such as salinity, drought, heavy metals, and others, as they can directly remove ROS or chelate metals [60]. However, phenolic metabolites are health-promoting compounds with therapeutic potential against many human diseases. For this reason, finding agents that could enhance the production by plants of secondary metabolites is not only an improved attribute for the plant itself, but it deserves attention as it can improve the nutraceutical values of crops $[63,64]$. In this 
context, our results revealed interesting increases in the content of anthocyanin and TP at the highest dosages applied for seed nano-priming (T2, T3, and T4). This effect has been documented in plants exposed to $\mathrm{ZnO}-\mathrm{NP}$, which, for the properties of its valence electrons, can absorb close to $400 \mathrm{~nm}$ and promote photo-oxidative processes [65]. In particular, $\mathrm{ZnO}$ NP show an intense absorption in the range of 370-390 nm, depending on the nanoparticles dimensions, size, and surface [46]. As for phenols, the mechanisms activated in response to nanoparticle treatment are largely unknown, although some experimental evidence indicates that ZnO-NPs may regulate phenols synthesis at the transcriptional level [64]. In addition, $\mathrm{ZnO}-\mathrm{NP}$ can give rise to ROS production, which may increase the antioxidants and secondary metabolites [66]. Nevertheless, due to the protective role of phenols in plants and their effect on their qualitative profile of crops, an increase in their content deserves attention.

Table 3. Effects of the nano-priming treatments with different concentrations of ZnO@LNP on the content of anthocyanin, total phenols (TP), DPPH, and MDA (T1, T2, T3, T4, and T5 refer to ZnO@LNP concentration used for seed nano-priming).

\begin{tabular}{|c|c|c|c|c|}
\hline & Anthocyanin & $\mathrm{TP}\left(\mathrm{mg} \mathrm{g}^{-1} \mathrm{FW}\right)$ & DPPH & MDA \\
\hline & $\left(\mathrm{mg} \mathrm{g}^{-1} \mathrm{FW}\right)$ & (Gallic Acid Equivalents) & (Scavenging Rate \%) & $\left(\mathrm{nmol} \mathrm{g}^{-1} \mathrm{FW}\right)$ \\
\hline Control & $0.14 \pm 0.01^{c}$ & $0.76 \pm 0.04^{c}$ & $65.3 \pm 1.6^{b}$ & $12.2 \pm 1.0^{\mathrm{a}}$ \\
\hline $\mathrm{T} 1$ & $0.16 \pm 0.03^{a b c}$ & $0.79 \pm 0.02^{\mathrm{c}}$ & $72.8 \pm 2.9^{a}$ & $13.1 \pm 1.2^{\mathrm{a}}$ \\
\hline $\mathrm{T} 2$ & $0.17 \pm 0.01^{\mathrm{ab}}$ & $0.86 \pm 0.02^{b}$ & $74.1 \pm 1.3^{\mathrm{a}}$ & $10.1 \pm 0.7^{b}$ \\
\hline $\mathrm{T} 3$ & $0.18 \pm 0.01^{\mathrm{ab}}$ & $0.85 \pm 0.04^{b}$ & $73.9 \pm 0.9^{a}$ & $9.2 \pm 0.6^{b c}$ \\
\hline $\mathrm{T} 4$ & $0.20 \pm 0.02^{\mathrm{a}}$ & $0.95 \pm 0.02^{\mathrm{a}}$ & $76.4 \pm 1.0^{\mathrm{a}}$ & $8.8 \pm 0.6^{c}$ \\
\hline
\end{tabular}

In each column and for each parameter, mean values followed by different letters are significantly different $(p<0.05)$.

Finally, the DPPH antioxidant activity and MDA content in nano-primed seedlings with T1, T2, T3, and T4 were determined (Table 3). The DPPH activity is routinely assessed to evidence the antioxidant activity following the exposure to abiotic and biotic stress or the effect of different treatments [67]. The results obtained in this study are consistent, since what was observed for carotenoids, anthocyanin, and TP aligned with the increases in the DPPH activity following the treatment with ZnO@LNP. Therefore, it can be reasonably supposed that the stimulatory effect of the hybrid regarded mainly the antioxidant activities thanks to the documented ability of ZnO-NP to give rise to oxidative perturbations, that, however, if reaching sub-toxic levels can promote beneficial effects on treated plants $[46,67]$.

The last aspect investigated in this study was the content of malondialdehyde (MDA), which is a product of lipid peroxidation. Results evidenced that nano-primed maize with T2, T3, and T4 significantly decreased the MDA compared to control samples. This result is indicative of the effectiveness of ZnO@LNP treatments in potentiating the antioxidant responses in primed seeds. MDA is commonly produced in chloroplasts and mitochondria, where metabolic processes characterized by high electron flow occur $[28,68]$. In stressful situations, usually, plants increase the content of molecules and enzymes with antioxidant action [63]. MDA accumulates when oxidative stress is particularly severe, and antioxidant defenses fail to contain ROS [46]. Therefore, the MDA estimation becomes important, as it indicates the cell's oxidative state. The results obtained in this study agree with the profile of the antioxidants investigated (Tables 2 and 3) and shed light on the capacity of the ZnO@LNP to ameliorate the oxidative status of nano-primed seeds. Other studies have attributed such a beneficial effect on lipid peroxidation containment to the capacity of nanomaterials to stimulate antioxidant activities $[29,48]$. These aspects should receive attention as the treatment with nanomaterials by foliar application or nano-priming can also be a strategy to prepare plants to cope with abiotic or biotic stresses by improving their antioxidant defenses. 


\section{Conclusions}

The use of nanomaterials as nanocarriers is gaining attention in agriculture, where they have recently been introduced. These new nanosystems stimulate plant growth and development, opening new perspectives in using nanoparticles [69]. The objective of this work was to realize a hybrid consisting of lignin and $\mathrm{ZnO}$, both in nanoparticle form. The hybrid function was to deliver and release bioactive zinc oxide nanoparticles to plants with the scope of biofortifying the treated species. To this end, after the hybrid synthesis, $\mathrm{ZnO} @ \mathrm{LNP}$ were applied at different concentrations using nano-priming technology. The beneficial effects recorded on maize at certain concentrations offer encouraging prospects. However, further studies are needed to understand and elucidate how these hybrid systems can exert these effects.

Author Contributions: Conceptualization, D.D.B., A.D.M., D.P.; investigation, D.D.B., A.D.M., F.L., C.T.; writing—original draft preparation, D.D.B., A.D.M., D.P., F.L., C.T.; writing-review and editing, D.D.B., A.D.M., D.P., F.L. All authors have read and agreed to the published version of the manuscript.

Funding: This research received no external funding.

Conflicts of Interest: The authors declare no conflict of interest.

\section{References}

1. Puglia, D.; Pezzolla, D.; Gigliotti, G.; Torre, L.; Bartucca, M.L.; Del Buono, D. The Opportunity of Valorizing Agricultural Waste, through Its Conversion into Biostimulants, Biofertilizers, and Biopolymers. Sustainability 2021, 13, 2710. [CrossRef]

2. Del Buono, D. Can Biostimulants Be Used to Mitigate the Effect of Anthropogenic Climate Change on Agriculture? It Is Time to Respond. Sci. Total Environ. 2021, 751, 141763. [CrossRef]

3. Kasivelu, G.; Selvaraj, T.; Malaichamy, K.; Kathickeyan, D.; Shkolnik, D.; Chaturvedi, S. Nano-Micronutrients $\left[\gamma-\mathrm{Fe}_{2} \mathrm{O}_{3}(\mathrm{Iron})\right.$ and $\mathrm{ZnO}$ (Zinc)]: Green Preparation, Characterization, Agro-Morphological Characteristics and Crop Productivity Studies in Two Crops (Rice and Maize). New J. Chem. 2020, 44, 11373-11383. [CrossRef]

4. Ahmed, S.; Annu; Chaudhry, S.A.; Ikram, S. A Review on Biogenic Synthesis of ZnO Nanoparticles Using Plant Extracts and Microbes: A Prospect towards Green Chemistry. J. Photochem. Photobiol. B 2017, 166, 272-284. [CrossRef]

5. Sturikova, H.; Krystofova, O.; Huska, D.; Adam, V. Zinc, Zinc Nanoparticles and Plants. J. Hazard. Mater. 2018, 349, 101-110. [CrossRef]

6. Guha, T.; Gopal, G.; Kundu, R.; Mukherjee, A. Nanocomposites for Delivering Agrochemicals: A Comprehensive Review. J. Agric. Food Chem. 2020, 68, 3691-3702. [CrossRef]

7. Luzi, F.; Tortorella, I.; Di Michele, A.; Dominici, F.; Argentati, C.; Morena, F.; Torre, L.; Puglia, D.; Martino, S. Novel Nanocomposite PLA Films with Lignin/Zinc Oxide Hybrids: Design, Characterization, Interaction with Mesenchymal Stem Cells. Nanomaterials 2020, 10, 2176. [CrossRef]

8. Chi, Z.; Hao, L.; Dong, H.; Yu, H.; Liu, H.; Yu, H. The Innovative Application of Organosolv Lignin for Nanomaterial Modification to Boost Its Heavy Metal Detoxification Performance in the Aquatic Environment. Chem. Eng. J. 2020, 382, 122789. [CrossRef]

9. Schneider, W.D.H.; Dillon, A.J.P.; Camassola, M. Lignin Nanoparticles Enter the Scene: A Promising Versatile Green Tool for Multiple Applications. Biotechnol. Adv. 2021, 47, 107685. [CrossRef]

10. Yang, W.; Fortunati, E.; Gao, D.; Balestra, G.M.; Giovanale, G.; He, X.; Torre, L.; Kenny, J.M.; Puglia, D. Valorization of Acid Isolated High Yield Lignin Nanoparticles as Innovative Antioxidant/Antimicrobial Organic Materials. ACS Sustain. Chem. Eng. 2018, 6, 3502-3514. [CrossRef]

11. Del Buono, D.; Luzi, F.; Puglia, D. Lignin Nanoparticles: A Promising Tool to Improve Maize Physiological, Biochemical, and Chemical Traits. Nanomaterials 2021, 11, 846. [CrossRef]

12. Figueiredo, P.; Lintinen, K.; Hirvonen, J.T.; Kostiainen, M.A.; Santos, H.A. Properties and Chemical Modifications of Lignin: Towards Lignin-Based Nanomaterials for Biomedical Applications. Prog. Mater. Sci. 2018, 93, 233-269. [CrossRef]

13. Wang, H.; Qiu, X.; Liu, W.; Yang, D. Facile Preparation of Well-Combined Lignin-Based Carbon/ZnO Hybrid Composite with Excellent Photocatalytic Activity. Appl. Surf. Sci. 2017, 426, 206-216. [CrossRef]

14. Sharma, D.; Sabela, M.I.; Kanchi, S.; Mdluli, P.S.; Singh, G.; Stenström, T.A.; Bisetty, K. Biosynthesis of ZnO Nanoparticles Using Jacaranda Mimosifolia Flowers Extract: Synergistic Antibacterial Activity and Molecular Simulated Facet Specific Adsorption Studies. J. Photochem. Photobiol. B 2016, 162, 199-207. [CrossRef]

15. Sun, X.; Li, Q.; Jiang, J.; Mao, Y. Morphology-Tunable Synthesis of ZnO Nanoforest and Its Photoelectrochemical Performance. Nanoscale 2014, 6, 8769-8780. [CrossRef]

16. Pineda-Reyes, A.M.; Olvera, M.D.L.L. Synthesis of ZnO Nanoparticles from Water-in-Oil (w/o) Microemulsions. Mater. Chem. Phys. 2018, 203, 141-147. [CrossRef]

17. Klapiszewski, Ł.; Bula, K.; Dobrowolska, A.; Czaczyk, K.; Jesionowski, T. A high-density polyethylene container based on ZnO/lignin dual fillers with potential antimicrobial activity. Polymer Test. 2019, 73, 51-59. [CrossRef] 
18. Klapiszewski, Ł.; Grzabka-Zasadzińska, A.; Borysiak, S.; Jesionowski, T. Preparation and characterization of polypropylene composites reinforced by functional ZnO/lignin hybrid materials. Polymer Test. 2019, 79, 106058. [CrossRef]

19. Klapiszewska, I.; Parus, A.; Ławniczak, Ł.; Jesionowski, T.; Klapiszewski, Ł.; Ślosarczyk, A. Production of antibacterial cement

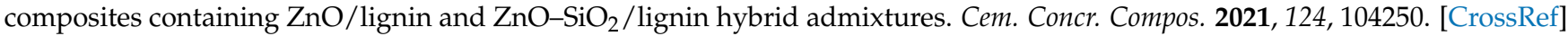

20. Kumar, S.; Nehra, M.; Dilbaghi, N.; Marrazza, G.; Hassan, A.A.; Kim, K.-H. Nano-Based Smart Pesticide Formulations: Emerging Opportunities for Agriculture. J. Control. Release 2019, 294, 131-153. [CrossRef]

21. Raliya, R.; Saharan, V.; Dimkpa, C.; Biswas, P. Nanofertilizer for Precision and Sustainable Agriculture: Current State and Future Perspectives. J. Agric. Food Chem. 2018, 66, 6487-6503. [CrossRef]

22. Sharma, A.; Sood, K.; Kaur, J.; Khatri, M. Agrochemical Loaded Biocompatible Chitosan Nanoparticles for Insect Pest Management. Biocatal. Agric. Biotechnol. 2019, 18, 101079. [CrossRef]

23. Parisi, C.; Vigani, M.; Rodríguez-Cerezo, E. Agricultural Nanotechnologies: What Are the Current Possibilities? Nano Today 2015, 10, 124-127. [CrossRef]

24. Sun, L.; Wang, Y.; Wang, R.; Wang, R.; Zhang, P.; Ju, Q.; Xu, J. Physiological, Transcriptomic, and Metabolomic Analyses Reveal Zinc Oxide Nanoparticles Modulate Plant Growth in Tomato. Environ. Sci. Nano 2020, 7, 3587-3604. [CrossRef]

25. Salama, D.M.; Osman, S.A.; Abd El-Aziz, M.E.; Abd Elwahed, M.S.A.; Shaaban, E.A. Effect of Zinc Oxide Nanoparticles on the Growth, Genomic DNA, Production and the Quality of Common Dry Bean (Phaseolus Vulgaris). Biocatal. Agric. Biotechnol. 2019, 18, 101083. [CrossRef]

26. do Espirito Santo Pereira, A.; Caixeta Oliveira, H.; Fernandes Fraceto, L.; Santaella, C. Nanotechnology Potential in Seed Priming for Sustainable Agriculture. Nanomaterials 2021, 11, 267. [CrossRef]

27. Navarro-López, E.; Ruíz-Nieto, A.; Ferreira, A.; Acién, F.G.; Gouveia, L. Biostimulant Potential of Scenedesmus Obliquus Grown in Brewery Wastewater. Molecules 2020, 25, 664. [CrossRef]

28. Panfili, I.; Bartucca, M.L.; Marrollo, G.; Povero, G.; Del Buono, D. Application of a Plant Biostimulant To Improve Maize (Zea Mays) Tolerance to Metolachlor. J. Agric. Food Chem. 2019, 67, 12164-12171. [CrossRef]

29. Venkatachalam, P.; Priyanka, N.; Manikandan, K.; Ganeshbabu, I.; Indiraarulselvi, P.; Geetha, N.; Muralikrishna, K.; Bhattacharya, R.C.; Tiwari, M.; Sharma, N.; et al. Enhanced Plant Growth Promoting Role of Phycomolecules Coated Zinc Oxide Nanoparticles with P Supplementation in Cotton (Gossypium Hirsutum L.). Plant Physiol. Biochem. 2017, 110, 118-127. [CrossRef]

30. Lichtenthaler, H.K.; Buschmann, C. Chlorophylls and Carotenoids: Measurement and Characterization by UV-VIS Spectroscopy. Curr. Protoc. Food Anal. Chem. 2001, 1, F4.3.1-F4.3.8. [CrossRef]

31. Parađiković, N.; Vinković, T.; Vinković Vrček, I.; Žuntar, I.; Bojić, M.; Medić-Šarić, M. Effect of Natural Biostimulants on Yield and Nutritional Quality: An Example of Sweet Yellow Pepper (Capsicum Annuum L.) Plants. J. Sci. Food Agric. 2011, 91, 2146-2152. [CrossRef]

32. Chollet, B.; Lopez-Cuesta, J.-M.; Laoutid, F.; Ferry, L. Lignin Nanoparticles as a Promising Way for Enhancing Lignin Flame Retardant Effect in Polylactide. Materials 2019, 12, 2132. [CrossRef]

33. Prieur, B.; Meub, M.; Wittemann, M.; Klein, R.; Bellayer, S.; Fontaine, G.; Bourbigot, S. Phosphorylation of Lignin: Characterization and Investigation of the Thermal Decomposition. RSC Adv. 2017, 7, 16866-16877. [CrossRef]

34. Bajwa, D.S.; Shojaeiarani, J.; Liaw, J.D.; Bajwa, S.G. Role of Hybrid Nano-Zinc Oxide and Cellulose Nanocrystals on the Mechanical, Thermal, and Flammability Properties of Poly (Lactic Acid) Polymer. J. Compos. Sci. 2021, 5, 43. [CrossRef]

35. Nagaraju, G.; Prashanth, S.A.; Shastri, M.; Yathish, K.V.; Anupama, C.; Rangappa, D. Electrochemical Heavy Metal Detection, Photocatalytic, Photoluminescence, Biodiesel Production and Antibacterial Activities of Ag-ZnO Nanomaterial. Mater. Res. Bull. 2017, 94, 54-63. [CrossRef]

36. Khalafi, T.; Buazar, F.; Ghanemi, K. Phycosynthesis and Enhanced Photocatalytic Activity of Zinc Oxide Nanoparticles Toward Organosulfur Pollutants. Sci. Rep. 2019, 9, 6866. [CrossRef]

37. Sowri Babu, K.; Ramachandra Reddy, A.; Sujatha, C.; Venugopal Reddy, K.; Mallika, A.N. Synthesis and Optical Characterization of Porous ZnO. J. Adv. Ceram. 2013, 2, 260-265. [CrossRef]

38. Jose, L.M.; Kuriakose, S.; Thomas, S. Fabrication, Characterization and In Vitro Antifungal Property Evaluation of Biocompatible Lignin-Stabilized Zinc Oxide Nanoparticles Against Selected Pathogenic Fungal Strains. BioNanoScience 2020, 10, 583-596. [CrossRef]

39. Kaur, R.; Thakur, N.S.; Chandna, S.; Bhaumik, J. Development of Agri-Biomass Based Lignin Derived Zinc Oxide Nanocomposites as Promising UV Protectant-Cum-Antimicrobial Agents. J. Mater. Chem. B 2020, 8, 260-269. [CrossRef]

40. Gerbin, E.; Rivière, G.N.; Foulon, L.; Frapart, Y.M.; Cottyn, B.; Pernes, M.; Marcuello, C.; Godon, B.; Gainvors-Claisse, A.; Crônier, D.; et al. Tuning the Functional Properties of Lignocellulosic Films by Controlling the Molecular and Supramolecular Structure of Lignin. Int. J. Biol. Macromol. 2021, 181, 136-149. [CrossRef]

41. Martins, N.C.T.; Avellan, A.; Rodrigues, S.; Salvador, D.; Rodrigues, S.M.; Trindade, T. Composites of Biopolymers and ZnO NPs for Controlled Release of Zinc in Agricultural Soils and Timed Delivery for Maize. ACS Appl. Nano Mater. 2020, 3, 2134-2148. [CrossRef]

42. Ye, Y.; Cota-Ruiz, K.; Hernández-Viezcas, J.A.; Valdés, C.; Medina-Velo, I.A.; Turley, R.S.; Peralta-Videa, J.R.; Gardea-Torresdey, J.L. Manganese Nanoparticles Control Salinity-Modulated Molecular Responses in Capsicum Annuum L. Through Priming: A Sustainable Approach for Agriculture. ACS Sustain. Chem. Eng. 2020, 8, 1427-1436. [CrossRef] 
43. Oracz, K.; Karpiński, S. Phytohormones Signaling Pathways and ROS Involvement in Seed Germination. Front. Plant Sci. 2016, 7, 864. [CrossRef]

44. Choudhary, R.C.; Kumaraswamy, R.V.; Kumari, S.; Sharma, S.S.; Pal, A.; Raliya, R.; Biswas, P.; Saharan, V. Zinc Encapsulated Chitosan Nanoparticle to Promote Maize Crop Yield. Int. J. Biol. Macromol. 2019, 127, 126-135. [CrossRef]

45. Večeřová, K.; Večeřa, Z.; Dočekal, B.; Oravec, M.; Pompeiano, A.; Tříska, J.; Urban, O. Changes of Primary and Secondary Metabolites in Barley Plants Exposed to CdO Nanoparticles. Environ. Pollut. 2016, 218, 207-218. [CrossRef]

46. Del Buono, D.; Di Michele, A.; Costantino, F.; Trevisan, M.; Lucini, L. Biogenic ZnO Nanoparticles Synthesized Using a Novel Plant Extract: Application to Enhance Physiological and Biochemical Traits in Maize. Nanomaterials 2021, 11, 1270. [CrossRef]

47. García-López, J.; Zavala-García, F.; Olivares-Sáenz, E.; Lira-Saldívar, R.; Díaz Barriga-Castro, E.; Ruiz-Torres, N.; Ramos-Cortez, E.; Vázquez-Alvarado, R.; Niño-Medina, G. Zinc Oxide Nanoparticles Boosts Phenolic Compounds and Antioxidant Activity of Capsicum Annuum L. during Germination. Agronomy 2018, 8, 215. [CrossRef]

48. Adhikari, S.; Adhikari, A.; Ghosh, S.; Roy, D.; Azahar, I.; Basuli, D.; Hossain, Z. Assessment of ZnO-NPs Toxicity in Maize: An Integrative MicroRNAomic Approach. Chemosphere 2020, 249, 126197. [CrossRef]

49. Lee, C.W.; Mahendra, S.; Zodrow, K.; Li, D.; Tsai, Y.-C.; Braam, J.; Alvarez, P.J.J. Developmental Phytotoxicity of Metal Oxide Nanoparticles to Arabidopsis Thaliana. Environ. Toxicol. Chem. 2010, 29, 669-675. [CrossRef]

50. Narendhran, S.; Rajiv, P.; Sivaraj, R. Toxicity of ZnO Nanoparticles on Germinating Sesamum Indicum (Co-1) and Their Antibacterial Activity. Bull. Mater. Sci. 2016, 39, 415-421. [CrossRef]

51. Guha, T.; Ravikumar, K.V.G.; Mukherjee, A.; Mukherjee, A.; Kundu, R. Nanopriming with Zero Valent Iron (NZVI) Enhances Germination and Growth in Aromatic Rice Cultivar (Oryza Sativa Cv. Gobindabhog L.). Plant Physiol. Biochem. 2018, 127, 403-413. [CrossRef]

52. Das, C.K.; Jangir, H.; Kumar, J.; Verma, S.; Mahapatra, S.S.; Philip, D.; Srivastava, G.; Das, M. Nano-Pyrite Seed Dressing: A Sustainable Design for NPK Equivalent Rice Production. Nanotechnol. Environ. Eng. 2018, 3, 14. [CrossRef]

53. Poynton, H.C.; Lazorchak, J.M.; Impellitteri, C.A.; Smith, M.E.; Rogers, K.; Patra, M.; Hammer, K.A.; Allen, H.J.; Vulpe, C.D Differential Gene Expression in Daphnia Magna Suggests Distinct Modes of Action and Bioavailability for Zno Nanoparticles and Zn Ions. Environ. Sci. Technol. 2011, 45, 762-768. [CrossRef]

54. El-Saadony, M.T.; Desoky, E.-S.M.; Saad, A.M.; Eid, R.S.M.; Selem, E.; Elrys, A.S. Biological Silicon Nanoparticles Improve Phaseolus Vulgaris L. Yield and Minimize Its Contaminant Contents on a Heavy Metals-Contaminated Saline Soil. J. Environ. Sci. China 2021, 106, 1-14. [CrossRef]

55. Manzoor, N.; Ahmed, T.; Noman, M.; Shahid, M.; Nazir, M.M.; Ali, L.; Alnusaire, T.S.; Li, B.; Schulin, R.; Wang, G. Iron Oxide Nanoparticles Ameliorated the Cadmium and Salinity Stresses in Wheat Plants, Facilitating Photosynthetic Pigments and Restricting Cadmium Uptake. Sci. Total Environ. 2021, 769, 145221. [CrossRef]

56. Singh, P.; Arif, Y.; Siddiqui, H.; Sami, F.; Zaidi, R.; Azam, A.; Alam, P.; Hayat, S. Nanoparticles Enhances the Salinity Toxicity Tolerance in Linum Usitatissimum L. by Modulating the Antioxidative Enzymes, Photosynthetic Efficiency, Redox Status and Cellular Damage. Ecotoxicol. Environ. Saf. 2021, 213, 112020. [CrossRef]

57. Changlian, P.; Zhifang, L.; Guizhu, L.; Shaowei, C. The Anti-Photooxidation of Anthocyanins-Rich Leaves of a Purple Rice Cultivar. Sci. China Ser. C Life Sci. 2006, 49, 543-551. [CrossRef]

58. Sonobe, R.; Yamashita, H.; Mihara, H.; Morita, A.; Ikka, T. Estimation of Leaf Chlorophyll a, b and Carotenoid Contents and Their Ratios Using Hyperspectral Reflectance. Remote Sens. 2020, 12, 3265. [CrossRef]

59. Bartucca, M.L.; Guiducci, M.; Falcinelli, B.; Del Buono, D.; Benincasa, P. Blue:Red LED Light Proportion Affects Vegetative Parameters, Pigment Content, and Oxidative Status of Einkorn (Triticum Monococcum L. Ssp. Monococcum) Wheatgrass. J. Agric. Food Chem. 2020, 68, 8757-8763. [CrossRef]

60. Gan, R.-Y.; Chan, C.-L.; Yang, Q.-Q.; Li, H.-B.; Zhang, D.; Ge, Y.-Y.; Gunaratne, A.; Ge, J.; Corke, H. Bioactive Compounds and Beneficial Functions of Sprouted Grains. In Sprouted Grains: Nutritional Value, Production, and Applications; Elsevier: Amsterdam, The Netherlands, 2018; pp. 191-246.

61. Ibrahim, A.B.M.; Mahmoud, G.A. Chemical- vs. Sonochemical-assisted Synthesis of ZnO Nanoparticles from a New Zinc Complex for Improvement of Carotene Biosynthesis from Rhodotorula Toruloides MH023518. Appl. Organomet. Chem. 2021, 35, e6086. [CrossRef]

62. Sofo, A.; Bochicchio, R.; Amato, M.; Rendina, N.; Vitti, A.; Nuzzaci, M.; Altamura, M.M.; Falasca, G.; Rovere, F.D.; Scopa, A. Plant Architecture, Auxin Homeostasis and Phenol Content in Arabidopsis Thaliana Grown in Cadmium- and Zinc-Enriched Media. J. Plant Physiol. 2017, 216, 174-180. [CrossRef]

63. Michalak, A. Phenolic Compounds and Their Antioxidant Activity in Plants Growing under Heavy Metal Stress. Pol. J. Environ. Stud. 2006, 15, 523-530.

64. Abbasi, B.H.; Zahir, A.; Ahmad, W.; Nadeem, M.; Giglioli-Guivarc'h, N.; Hano, C. Biogenic Zinc Oxide Nanoparticles-Enhanced Biosynthesis of Lignans and Neolignans in Cell Suspension Cultures of Linum Usitatissimum L. Artif. Cells Nanomed. Biotechnol. 2019, 47, 1367-1373. [CrossRef]

65. Bustos-Torres, K.A.; Vazquez-Rodriguez, S.; la Cruz, A.M.; Sepulveda-Guzman, S.; Benavides, R.; Lopez-Gonzalez, R.; TorresMartínez, L.M. Influence of the Morphology of ZnO Nanomaterials on Photooxidation of Polypropylene/ZnO Composites. Mater. Sci. Semicond. Process. 2017, 68, 217-225. [CrossRef] 
66. Xiang, L.; Zhao, H.-M.; Li, Y.-W.; Huang, X.-P.; Wu, X.-L.; Zhai, T.; Yuan, Y.; Cai, Q.-Y.; Mo, C.-H. Effects of the Size and Morphology of Zinc Oxide Nanoparticles on the Germination of Chinese Cabbage Seeds. Environ. Sci. Pollut. Res. 2015, 22, 10452-10462. [CrossRef]

67. Javed, R.; Usman, M.; Yücesan, B.; Zia, M.; Gürel, E. Effect of Zinc Oxide (ZnO) Nanoparticles on Physiology and Steviol Glycosides Production in Micropropagated Shoots of Stevia Rebaudiana Bertoni. Plant Physiol. Biochem. 2017, 110, 94-99. [CrossRef]

68. Del Buono, D.; Regni, L.; Del Pino, A.M.; Bartucca, M.L.; Palmerini, C.A.; Proietti, P. Effects of Megafol on the Olive Cultivar 'Arbequina' Grown Under Severe Saline Stress in Terms of Physiological Traits, Oxidative Stress, Antioxidant Defenses, and Cytosolic $\mathrm{Ca}^{2+}$. Front. Plant Sci. 2021, 11, 603576. [CrossRef]

69. Falsini, S.; Clemente, I.; Papini, A.; Tani, C.; Schiff, S.; Salvatici, M.C.; Petruccelli, R.; Benelli, C.; Giordano, C.; Gonnelli, C.; et al. When Sustainable Nanochemistry Meets Agriculture: Lignin Nanocapsules for Bioactive Compound Delivery to Plantlets. ACS Sustain. Chem. Eng. 2019, 7, 19935-19942. [CrossRef] 